\title{
Article \\ A Novel Three-Vector-Based Model Predictive Direct Power Control for Three-Phase PWM Rectifier
}

\author{
Liuchen Tai ${ }^{1, *}$, Mingyao Lin ${ }^{2}, \mathrm{Hui} \mathrm{Li}^{3}$ and Yongsheng Li ${ }^{4}$ \\ 1 College of Information and Control Engineering, Weifang University, Weifang 261061, China \\ 2 School of Electrical Engineering, Southeast University, Nanjing 210096, China; mylin@seu.edu.cn \\ 3 Electric Power Research Institute of Guangdong Power Grid Ltd., Guangzhou 510080, China; \\ lihuiseu@163.com \\ 4 Shandong Tianrui Heavy Industry Co., Ltd., Weifang 261061, China; tr9909@126.com \\ * Correspondence: tailiuchen@163.com; Tel.: +86-133-7105-5879
}

Citation: Tai, L.; Lin, M.; Li, H.; Li, Y. A Novel Three-Vector-Based Model Predictive Direct Power Control for Three-Phase PWM Rectifier. Electronics 2021, 10, 2579. https:// doi.org/10.3390/electronics10212579

Academic Editor: Ali Mehrizi-Sani

Received: 31 August 2021

Accepted: 19 October 2021

Published: 21 October 202

Publisher's Note: MDPI stays neutral with regard to jurisdictional claims in published maps and institutional affiliations.

Copyright: () 2021 by the authors. Licensee MDPI, Basel, Switzerland. This article is an open access article distributed under the terms and conditions of the Creative Commons Attribution (CC BY) license (https:// creativecommons.org/licenses/by/ $4.0 /)$.

\begin{abstract}
A novel strategy of three-vector-based model predictive direct power control (MPDPC) is proposed for three-phase Pulse-width Modulation (PWM) rectifier. Under ideal grid conditions, three-vector MPDPC is studied, and a good control effect has been achieved. However, under the unbalanced power grid condition, the traditional control strategy has some problems, such as a high harmonic content of current and large instantaneous power pulsation. A new three-vector model predictive control is proposed based on the new instantaneous power theory, and the objective function is established by instantaneous power error. The duty cycle of the selected vector is calculated by solving the optimal objective function. Under an unbalanced power grid, this paper takes a three-phase PWM rectifier as a research object, and carries out simulation and experimental tests on the traditional and new control strategies. The experimental results show that the new control strategy has lower current harmonics, and eliminates the twice grid-frequency oscillation of the grid in instantaneous power.
\end{abstract}

Keywords: three-phase PWM rectifier; three-vector; model predictive direct power control; new instantaneous power theory; unbalanced grid conditions

\section{Introduction}

In the discrete mathematical model of PWM rectifier, the model predictive control (MPC) predicts the grid side current, instantaneous power and other electrical quantities in the next control cycle; then the objective function is set according to the needs of the control system, an optimal voltage vector is obtained by solving the optimal objective function [1-6]. As a kind of predictive control, it has the advantages of not having a pulse width modulation module, flexible control scheme and high robust performance, and as such has aroused the interest of many scholars [7-12].

The finite control set model predictive direct power control (FCS-MPDPC) combines MPC with DPC [13-15]. The objective function of FCS-MPDPC is composed of the error term between the instantaneous power and the given value, and an appropriate voltage vector is selected by solving the optimal objective function, which improves the control performance of the rectifier while maintaining a fast dynamic response. However, this method uses one voltage vector in a switching cycle. To achieve better control performance, the sampling frequency of the control system must be increased. Reference [6] proposed a FCS-MPDPC, based on duty cycle optimization, which is also known as two-vector FCSMPDPC. Different from the traditional FCS-MPDPC, the control method uses a zero vector and a non-zero vector in one cycle, and uses the zero-vector to regulate the instantaneous power smoothly. The two-vector FCS-MPDPC can maintain a fast dynamic response under the same sampling frequency, and at the same time reduce the current harmonic content and reduce the instantaneous power pulsation. Reference [16] also proposes a 
two-vector FCS-MPDPC. The main difference between reference [16] and reference [6] is that reference [6] takes the minimum sum of squares of instantaneous power error as the optimization objective, while reference [16] takes the minimum instantaneous active power ripple as the control objective. These two strategies can achieve good control effect, but there is a certain coupling relationship in the control of instantaneous power. That is, when the instantaneous active power changes suddenly, it will affect the control of instantaneous reactive power, and even cause a fluctuation of instantaneous reactive power, and vice versa.

To solve this problem, a power decoupled FCS-MPDPC is proposed in reference [17]. In this algorithm, weight coefficients are introduced into the instantaneous power error terms, and the weight coefficients will change with the changes in instantaneous power errors. The two-vector in references [6], [16] and [17] are composed of the zero-vector. Based on the principle of volt second balance, the two-vector cannot synthesize the voltage vector of any angle in the plane, so they cannot fully meet the requirements of gridconnected control of PWM rectifier. Therefore, a new type of FCS-MPDPC is proposed in reference [18], that is, a non-zero-vector can be combined not only with zero-vector, but also with adjacent non-zero vectors. There are 12 different vector combinations. Through the expansion of a vector combination, the algorithm can reduce the instantaneous power ripple and the harmonic content of current to a certain extent, but it cannot achieve a fixed switching frequency. In reference [19], a three-vector FCS-MPDPC is proposed, which uses two non-zero vectors and one zero-vector. This algorithm has the advantages of high sinusoidal current, small instantaneous power ripple and the switching frequency is fixed. In reference [20], a three-vector FCS-MPDPC is proposed to optimize the switching sequence. Different from reference [19], the algorithm needs to predict the instantaneous power under 12 different vector combinations, and sets an objective function, based on the global power error, that is, to accumulate the sum of squares of the instantaneous power error terms in each switching action in a control cycle. Although the algorithm can further suppress the power ripple, reduce the total harmonic distortion (THD) and obtain a fixed switching frequency, it needs to predict the instantaneous power twelve times, which is complex and requires high processing speed of the control chip.

In addition, under three-phase unbalanced power grid condition, the negative sequence component will appear in the grid voltage. If the traditional FCS-MPDPC is still used, the THD of the grid side current will be larger and the instantaneous power ripple will be larger. Therefore, based on the new instantaneous power theory, a new three-vector FCS-MPDPC is proposed.

\section{Mathematical Model of PWM Rectifier}

Figure 1 is the three-phase PWM rectifier. Among them, $e_{a}, e_{b}$ and $e_{c}$ are three-phase grid voltage, $i_{a}, i_{b}$ and $i_{c}$ are three-phase grid current, $v_{a}, v_{b}$ and $v_{c}$ are three-phase bridge arm output voltage of PWM rectifier. $L$ is inductance. $R$ is parasitic resistance.

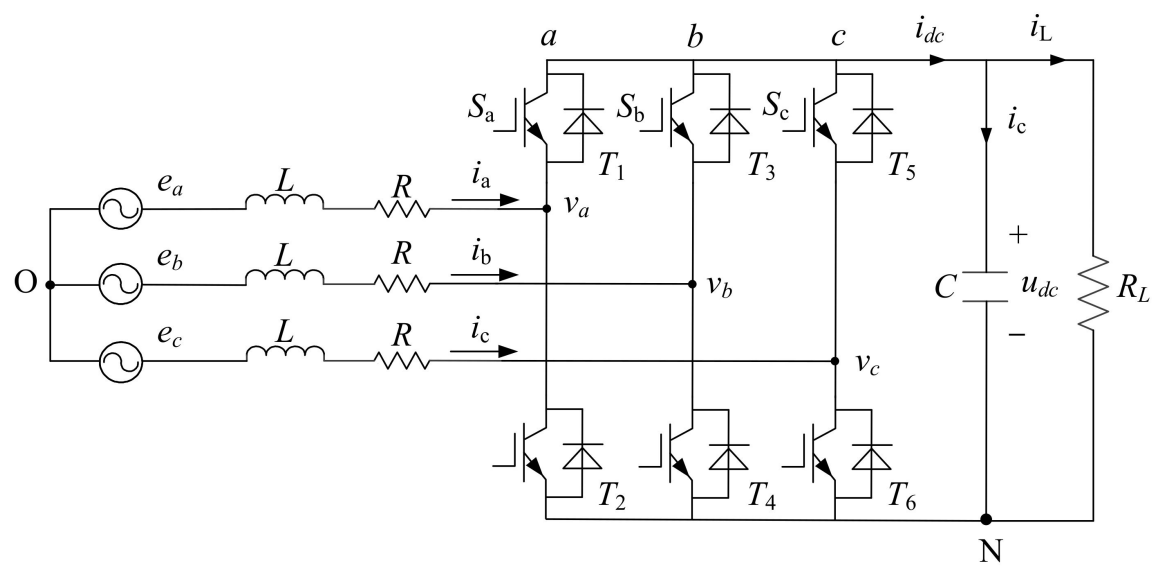

Figure 1. Three-phase PWM rectifier. 
Based on Kirchhoff voltage law, the voltage loop equation of AC side of PWM rectifier is:

$$
\left\{\begin{array}{l}
L \frac{d i_{a}}{d t}+R i_{a}=e_{a}-v_{a} \\
L \frac{d i_{b}}{d t}+R i_{b}=e_{b}-v_{b} \\
L \frac{d i_{c}}{d t}+R i_{c}=e_{c}-v_{c}
\end{array}\right.
$$

The corresponding vector equation is:

$$
\boldsymbol{E}=L \frac{d \boldsymbol{I}}{d t}+R \boldsymbol{I}+\boldsymbol{V}
$$

where, $E$ means the three-phase grid voltage vector. $I$ means the three-phase grid current vector. $V$ means the AC side output voltage vector of PWM rectifier.

Through abc/ $\alpha \beta$ coordinate transformation, the PWM rectifier in the $\alpha \beta$ coordinate system is:

$$
\left\{\begin{array}{l}
L \frac{\mathrm{d} i_{\alpha}}{\mathrm{d} t}=e_{\alpha}-R i_{\alpha}-v_{\alpha} \\
L \frac{\mathrm{d} i_{\beta}}{\mathrm{d} t}=e_{\beta}-R i_{\beta}-v_{\beta}
\end{array}\right.
$$

where, $e_{\alpha}$ and $e_{\beta}$ are components of $\boldsymbol{E}, i_{\alpha}$ and $i_{\beta}$ are components of $\boldsymbol{I}$, and $v_{\alpha}$ and $v_{\beta}$ are components of $\boldsymbol{V}$.

When the three-phase grid is unbalanced, the fundamental component is considered, in $d q$ coordinate system the $\boldsymbol{E}$ is:

$$
\boldsymbol{E}=e^{j \omega t} E_{d q}^{P}+e^{-j \omega t} E_{d q}^{N}
$$

where, $E_{d q}^{P}$ and $E_{d q}^{N}$ are the fundamental voltage component of positive sequence and negative sequence.

Assuming that both $\boldsymbol{V}$ and $\boldsymbol{I}$ have positive and negative sequence components, we can get the following conclusion:

$$
\left\{\begin{array}{l}
\boldsymbol{V}=e^{j \omega t} V_{d q}^{P}+e^{-j \omega t} V_{d q}^{N} \\
\boldsymbol{I}=e^{j \omega t} I_{d q}^{P}+e^{-j \omega t} I_{d q}^{N}
\end{array}\right.
$$

where, $V_{d q}^{P}$ and $V_{d q}^{N}$ are positive sequence and negative sequence fundamental voltage components, respectively, $I_{d q}^{P}$ and $I_{d q}^{N}$ are positive sequence and negative sequence fundamental current components, respectively.

\subsection{Traditional Instantaneous Power in dq Coordinate System}

Based on the instantaneous power theory [21], the complex power $S$ is:

$$
S=1.5 I^{*} E=1.5\left(e^{j \omega t} I_{d q}^{P}+e^{-j \omega t} I_{d q}^{N}\right)^{*}\left(e^{j \omega t} E_{d q}^{P}+e^{-j \omega t} E_{d q}^{N}\right)
$$

where, "**" denotes the conjugation of related variables. The instantaneous active and reactive power expressions is:

$$
\left\{\begin{array}{l}
p=1.5 \operatorname{Re}\left(\boldsymbol{I}^{*} \boldsymbol{E}\right)=p_{0}+p_{c 2} \cos (2 \omega t)+p_{s 2} \sin (2 \omega t) \\
q=1.5 \operatorname{Im}\left(\boldsymbol{I}^{*} \boldsymbol{E}\right)=q_{0}+q_{c 2} \cos (2 \omega t)+q_{s 2} \sin (2 \omega t)
\end{array}\right.
$$

where, $p_{0}$ and $q_{0}$ are the DC components of instantaneous power, $p_{\mathrm{c} 2}$ and $q_{\mathrm{c} 2}$ are cosine components peak of the second order of instantaneous power, $p_{s 2}$ and $q_{s 2}$ are sine components peak of the second order of instantaneous power. 
Further, the peak value of each component can be deduced as follows:

$$
\left\{\begin{array}{l}
p_{0}=1.5\left(E_{d q}^{P} \odot I_{d q}^{P}+E_{d q}^{N} \odot I_{d q}^{N}\right)=1.5\left(e_{d}^{P} i_{d}^{P}+e_{q}^{P} i_{q}^{P}+e_{d}^{N} i_{d}^{N}+e_{q}^{N} i_{q}^{N}\right) \\
p_{c 2}=1.5\left(E_{d q}^{N} \odot I_{d q}^{P}+E_{d q}^{P} \odot I_{d q}^{N}\right)=1.5\left(e_{d}^{P} i_{d}^{N}+e_{q}^{P} i_{q}^{N}+e_{d}^{N} i_{d}^{P}+e_{q}^{N} i_{q}^{P}\right) \\
p_{s 2}=1.5\left(E_{d q}^{N} \otimes I_{d q}^{P}-E_{d q}^{P} \otimes I_{d q}^{N}\right)=1.5\left(e_{q}^{N} i_{d}^{P}-e_{d}^{N} i_{q}^{P}-e_{q}^{P} i_{d}^{N}+e_{d}^{P} i_{q}^{N}\right) \\
q_{0}=1.5\left(E_{d q}^{P} \otimes I_{d q}^{P}+E_{d q}^{N} \otimes I_{d q}^{N}\right)=1.5\left(e_{q}^{P} i_{d}^{P}-e_{d}^{P} i_{q}^{P}+e_{q}^{N} i_{d}^{N}-e_{d}^{N} i_{q}^{N}\right) \\
q_{c 2}=1.5\left(E_{d q}^{N} \otimes I_{d q}^{P}+E_{d q}^{P} \otimes I_{d q}^{N}\right)=1.5\left(e_{q}^{P} i_{d}^{N}-e_{d}^{P} i_{q}^{N}+e_{q}^{N} i_{d}^{P}-e_{d}^{N} i_{q}^{P}\right) \\
q_{s 2}=1.5\left(-E_{d q}^{N} \odot I_{d q}^{P}+E_{d q}^{P} \odot I_{d q}^{N}\right)=1.5\left(e_{q}^{P} i_{d}^{N}+e_{d}^{P} i_{q}^{N}-e_{q}^{N} i_{d}^{P}-e_{d}^{N} i_{q}^{P}\right)
\end{array}\right.
$$

where, $e_{d}^{P}$ and $e_{q}^{P}$ are the projection of $E_{d q}^{P}$ on the dq axis respectively. $e_{d}^{N}$ and $e_{q}^{N}$ are respectively the projection of $E_{d q}^{N}$ on the dq axis. $i_{d}^{P}$ and $i_{q}^{P}$ are the projection of $I_{d q}^{P}$ on the dq axis. $i_{d}^{N}$ and $i_{q}^{N}$ are the projection of $I_{d q}^{N}$ on the dq axis.

Equation (8) shows $\boldsymbol{I}$ only contains four components $\left(i_{d}^{P}, i_{q}^{P}, i_{d}^{N}, i_{q}^{N}\right)$ under unbalanced grid conditions, which cannot meet the control requirements of the six components of instantaneous power at the same time. If the control objective is to suppress the second harmonic component of $p$, the $q$ will contain the second harmonic component, and the traditional FCS-MPDPC will not be applicable.

\subsection{New Instantaneous Power in $d q$ Coordinate System}

To solve above problems, the new instantaneous power theory is used [22]. In the new instantaneous power, the instantaneous active power is equivalent to the traditional instantaneous active power, but the new instantaneous reactive power is:

$$
q^{\text {nov }}=1.5 \operatorname{Re}\left(\boldsymbol{I}^{*} \boldsymbol{E}^{\prime}\right)
$$

where, $\boldsymbol{E}^{\prime}$ is the vector with $90^{\circ} \operatorname{lag} \boldsymbol{E}$, which is:

$$
\boldsymbol{E}^{\prime}=-j E_{d q}^{P} e^{j \omega t}+j E_{d q}^{N} e^{-j \omega t}
$$

Thus, the $q^{\text {nov }}$ can be deduced as:

$$
q^{n o v}(t)=q_{0}^{n o v}+q_{c 2}^{n o v} \cos (2 \omega t)+q_{s 2}^{n o v} \sin (2 \omega t)
$$

where,

$$
\left\{\begin{array}{l}
q_{0}^{n o v}=1.5\left(E_{d q}^{P} \otimes I_{d q}^{P}-E_{d q}^{N} \otimes I_{d q}^{N}\right)=1.5\left(e_{q}^{P} i_{d}^{P}-e_{d}^{P} i_{q}^{P}-e_{q}^{N} i_{d}^{N}+e_{d}^{N} i_{q}^{N}\right) \\
q_{c 2}^{n o v}=1.5\left(-E_{d q}^{N} \otimes I_{d q}^{P}+E_{d q}^{P} \otimes I_{d q}^{N}\right)=1.5\left(e_{d}^{N} i_{q}^{P}-e_{q}^{N} i_{d}^{P}+e_{q}^{P} i_{d}^{N}-e_{d}^{P} i_{q}^{N}\right) \\
q_{s 2}^{n o v}=1.5\left(E_{d q}^{N} \odot I_{d q}^{P}+E_{d q}^{P} \odot I_{d q}^{N}\right)=1.5\left(e_{d}^{N} i_{d}^{P}+e_{q}^{N} i_{q}^{P}+e_{q}^{P} i_{d}^{N}+e_{q}^{P} i_{q}^{N}\right)
\end{array}\right.
$$

By comparing Equation (8) with Equation (12), it can be seen that $p_{c 2}=q_{s 2}^{\text {nov }}$ and $p_{s 2}=-q_{c 2}^{n o v}$. When the instantaneous active power output of PWM rectifier has no pulsation component, the instantaneous reactive power output also has no pulsation component, which can realize the new instantaneous power are constant under the condition of unbalanced power grid.

\section{New FCS-MPDPC}

The new instantaneous power in the $\alpha \beta$ coordinate system is:

$$
\left[\begin{array}{c}
p \\
q^{n o v}
\end{array}\right]=1.5\left[\begin{array}{cc}
e_{\alpha} & e_{\beta} \\
e_{\alpha}^{\prime} & e_{\beta}^{\prime}
\end{array}\right]\left[\begin{array}{l}
i_{\alpha} \\
i_{\beta}
\end{array}\right]
$$


where, $e_{\alpha}^{\prime}$ and $e_{\beta}^{\prime}$ are the components of $E^{\prime}$.

According to Equation (13), the change rate of the new instantaneous power is:

$$
\left\{\begin{array}{l}
\frac{d p}{d t}=1.5\left(\frac{d e_{\alpha}}{d t} i_{\alpha}+e_{\alpha} \frac{d i_{\alpha}}{d t}+\frac{d e_{\beta}}{d t} i_{\beta}+e_{\beta} \frac{d i_{\beta}}{d t}\right) \\
\frac{d q^{n o v}}{d t}=1.5\left(\frac{d e_{\alpha}^{\prime}}{d t} i_{\alpha}+e_{\alpha}^{\prime} \frac{d i_{\alpha}}{d t}+\frac{d e_{\beta}^{\prime}}{d t} i_{\beta}+e_{\beta}^{\prime} \frac{d i_{\beta}}{d t}\right)
\end{array}\right.
$$

Under unbalanced power grid condition, the differential form of $E$ is:

$$
\frac{d E}{d t}=j \omega E_{d q}^{P} e^{j \omega t}-j \omega E_{d q}^{N} e^{-j \omega t}
$$

Substituting Equation (4) into Equation (15) obtains:

$$
\frac{d E}{d t}=-\omega E^{\prime}
$$

According to Equation (16), the rate of change of $\alpha$ and $\beta$ components of $E$ in the static $\alpha \beta$ coordinate system is:

$$
\left\{\begin{array}{l}
\frac{d e_{\alpha}}{d t}=-\omega e_{\alpha}^{\prime} \\
\frac{d e_{\beta}}{d t}=-\omega e_{\beta}^{\prime}
\end{array}\right.
$$

Similarly, the rate of change of $\boldsymbol{E}^{\prime}$ in the $\alpha \beta$ coordinate system is:

$$
\left\{\begin{array}{l}
\frac{d e_{\alpha}^{\prime}}{d t}=\omega e_{\alpha} \\
\frac{d e_{\beta}^{\prime}}{d t}=\omega e_{\beta}
\end{array}\right.
$$

Combined with Equations (3), (14), (17) and (18), the differential expression of the new instantaneous power can be written as:

$$
\left\{\begin{array}{c}
\frac{d p}{d t}=\frac{1.5}{L}\left(e_{\alpha}^{2}+e_{\beta}^{2}-e_{\alpha} v_{\alpha}-e_{\beta} v_{\beta}\right)-\frac{R}{L} p-\omega q^{\text {nov }} \\
\frac{d q^{n o v}}{d t}=\frac{1.5}{L}\left(e_{\alpha} e_{\alpha}^{\prime}+e_{\beta} e_{\beta}^{\prime}-v_{\alpha} e_{\alpha}^{\prime}-v_{\beta} e_{\beta}^{\prime}\right)-\frac{R}{L} q^{n o v}+\omega p
\end{array}\right.
$$

According to Equation (19), the change rate under the action of each voltage vector is calculated as follows:

$$
\left\{\begin{array}{l}
s_{p i}=\frac{d p}{d t} \mid\left(V_{i}\right)=\frac{1.5}{L}\left(e_{\alpha}^{2}+e_{\beta}^{2}-e_{\alpha} v_{\alpha-i}-e_{\beta} v_{\beta-i}\right)-\frac{R}{L} p-\omega q^{n o v} \\
s_{q i}=\frac{d q^{n o v}}{d t} \mid\left(V_{i}\right)=\frac{1.5}{L}\left(e_{\alpha} e_{\alpha}^{\prime}+e_{\beta} e_{\beta}^{\prime}-v_{\alpha-i} e_{\alpha}^{\prime}-v_{\beta-i} e_{\beta}^{\prime}\right)-\frac{R}{L} q^{n o v}+\omega p
\end{array} \quad i \in[0,7]\right.
$$

Figure 2 shows the change of instantaneous power rate with the phase Angle of $E$ under the action of eight different voltage vectors $\left(V_{0}-V_{7}\right)$. As can be seen from Figure 2, in the case of grid unbalance, the instantaneous power change rate corresponding to the two zero voltage vectors is not constant, but a pulsating component. 

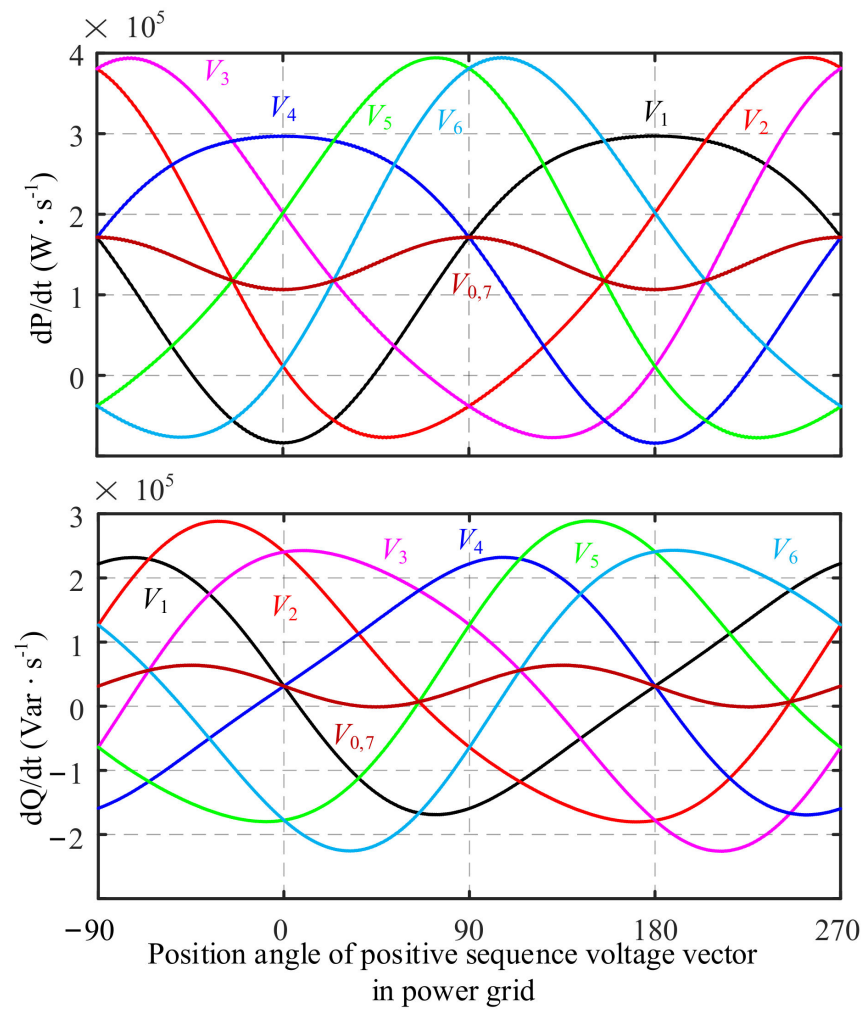

Figure 2. New instantaneous power slopes of various rectifier voltage vectors.

To achieve the goal that the new instantaneous power output of the PWM rectifier follows the given value; the objective function is composed of the error term of this new instantaneous power and the given value. The objective function is:

$$
c f=\left(p_{r e f}-p_{k+1}\right)^{2}+\left(q_{r e f}^{n o v}-q_{k+1}^{n o v}\right)^{2}
$$

In the Equation (21), $p_{k+1}$ and $q_{k+1}^{n o v}$ are the predicted values of $p$ and $q^{\text {nov }}$ in the next control period, respectively. $p_{r e f}$ and $q_{r e f}^{n o v}$ are given values, respectively.

A three-vector FCS-MPDPC is proposed, in a control cycle one zero vector and two adjacent non-zero voltage vectors are selected. There are six different combination modes of two non-zero vectors, namely $\left\{V_{1}, V_{2}\right\},\left\{V_{2}, V_{3}\right\}, \ldots,\left\{V_{6}, V_{1}\right\}$. Based on the three voltage vectors, the control system needs to select the most suitable group from these six combinations, and generate six PWM control signals, according to the action time and action sequence of each vector.

The selection and the calculation of action time of the vector occur at the same time. Before the most suitable vector combination is obtained, the action time of each vector needs to be calculated, and then the instantaneous power of the next control cycle corresponding to the vector combination is predicted. Finally, the most suitable voltage vector combination is selected by the smallest objective function.

Assuming that the optimal non-zero vector combination in a current control cycle is $\left\{V_{1}, V_{2}\right\} . V_{0}$ is the zero vector, the vector combination used by the control system is $\left\{V_{1}, V_{2}, V_{0}\right\}$. The change rates of instantaneous active power corresponding to the voltage vector combination $\left\{\boldsymbol{V}_{1}, \boldsymbol{V}_{2}, \boldsymbol{V}_{0}\right\}$ are $s_{p 1}, s_{p 2}$, and $s_{p 0}$, respectively, and the corresponding instantaneous reactive power change rates are $s_{q 1}, s_{q 2}, s_{q 0}$, then the instantaneous rate in the next control cycle. The predicted value of power is as follows:

$$
\left\{\begin{array}{l}
p_{k+1}=p_{k}+s_{p 1} \cdot t_{1}+s_{p 2} \cdot t_{2}+s_{p 0} \cdot\left(T_{s}-t_{1}-t_{2}\right) \\
q_{k+1}=q_{k}+s_{q 1} \cdot t_{1}+s_{q 2} \cdot t_{2}+s_{q 0} \cdot\left(T_{s}-t_{1}-t_{2}\right)
\end{array}\right.
$$


where, $T_{\mathrm{s}}$ means the control period. $t_{1}$ and $t_{2}$ are the action time of $\boldsymbol{V}_{1}$ and $\boldsymbol{V}_{2}$, respectively.

Since the control goal of model prediction is to minimize $c f$, the minimum $c f$ in Equation (21) is used as the constraint condition, the time of each non-zero vector should satisfy:

$$
\left\{\begin{array}{l}
\frac{\partial c f}{\partial t_{1}}=0 \\
\frac{\partial c f}{\partial t_{2}}=0
\end{array}\right.
$$

By solving the Equation (23), the action time of $V_{1}$ and $V_{2}$ was found to be:

$$
\left\{\begin{array}{l}
t_{1}=\frac{\left(s_{q 2}-s_{q 0}\right)\left(p_{r e f}-p_{k+1}\right)+\left(s_{p 0}-s_{p 2}\right)\left(q_{r e f}-q_{k+1}\right)+\left(s_{q 0} s_{p 2}-s_{q 2} s_{p 0}\right) T_{s}}{\left(s_{q 2}-s_{q 0}\right) s_{p 1}-\left(s_{q 1}-s_{q 0}\right) s_{p 2}-\left(s_{q 2}-s_{q 1}\right) s_{p 0}} \\
t_{2}=\frac{\left(s_{q 0}-s_{q 1}\right)\left(p_{r e f}-p_{k+1}\right)+\left(s_{p 1}-s_{p 0}\right)\left(q_{r e f}-q_{k+1}\right)+\left(s_{q 1} s_{p 0}-s_{q 0} s_{p 1}\right) T_{s}}{\left(s_{q 2}-s_{q 0}\right) s_{p 1}-\left(s_{q 1}-s_{q 0}\right) s_{p 2}-\left(s_{q 2}-s_{q 1}\right) s_{p 0}}
\end{array}\right.
$$

After obtaining the action time $t_{1}$ and $t_{2}$, when $t_{1}$ or $t_{2}$ is less than zero, then $t_{1}$ or $t_{2}$ is equal to zero; when $t_{1}$ or $t_{2}$ is greater than $T_{\mathrm{s}}$, then $t_{1}$ or $t_{2}$ is equal to $T_{\mathrm{s}}$. After simply processing $t_{1}$ and $t_{2}$ of the non-zero voltage vector, when $t_{1}+t_{2}>T_{\mathrm{s}}$, the action time $t_{0}, t_{1}$ and $t_{2}$ should be adjusted to:

$$
\left\{\begin{array}{l}
t_{1}=\frac{t_{1}}{t_{1}+t_{2}} T_{S} \\
t_{2}=\frac{t_{2}}{t_{1}+t_{2}} T_{S} \\
t_{0}=T_{s}-t_{1}-t_{2}
\end{array}\right.
$$

Substituting Equation (25) into Equation (22), the predicted value of instantaneous power under the action of the voltage vector combination $\left\{\boldsymbol{V}_{1}, \boldsymbol{V}_{2}, \boldsymbol{V}_{0}\right\}$ can be calculated. Then combine Equation (21) to get the corresponding objective function value $c f_{1}$. In the same way, the values $c f_{2}, c f_{3}, \ldots, c f_{6}$ of the objective function under the action of other vector combinations can be calculated. To minimize the instantaneous power error, the voltage vector combination corresponding to the minimum $c f$ is the optimal voltage vector combination. When the optimal voltage vector combination is determined, it can be modulated according to the SVPWM method.

Figure 3 is the new FCS-MPDPC control diagram, which is mainly divided into six key links, such as delay vector solution, new instantaneous power calculation, new instantaneous power prediction, objective function optimization, voltage vector selection and operation time calculation and pulse width modulation. 


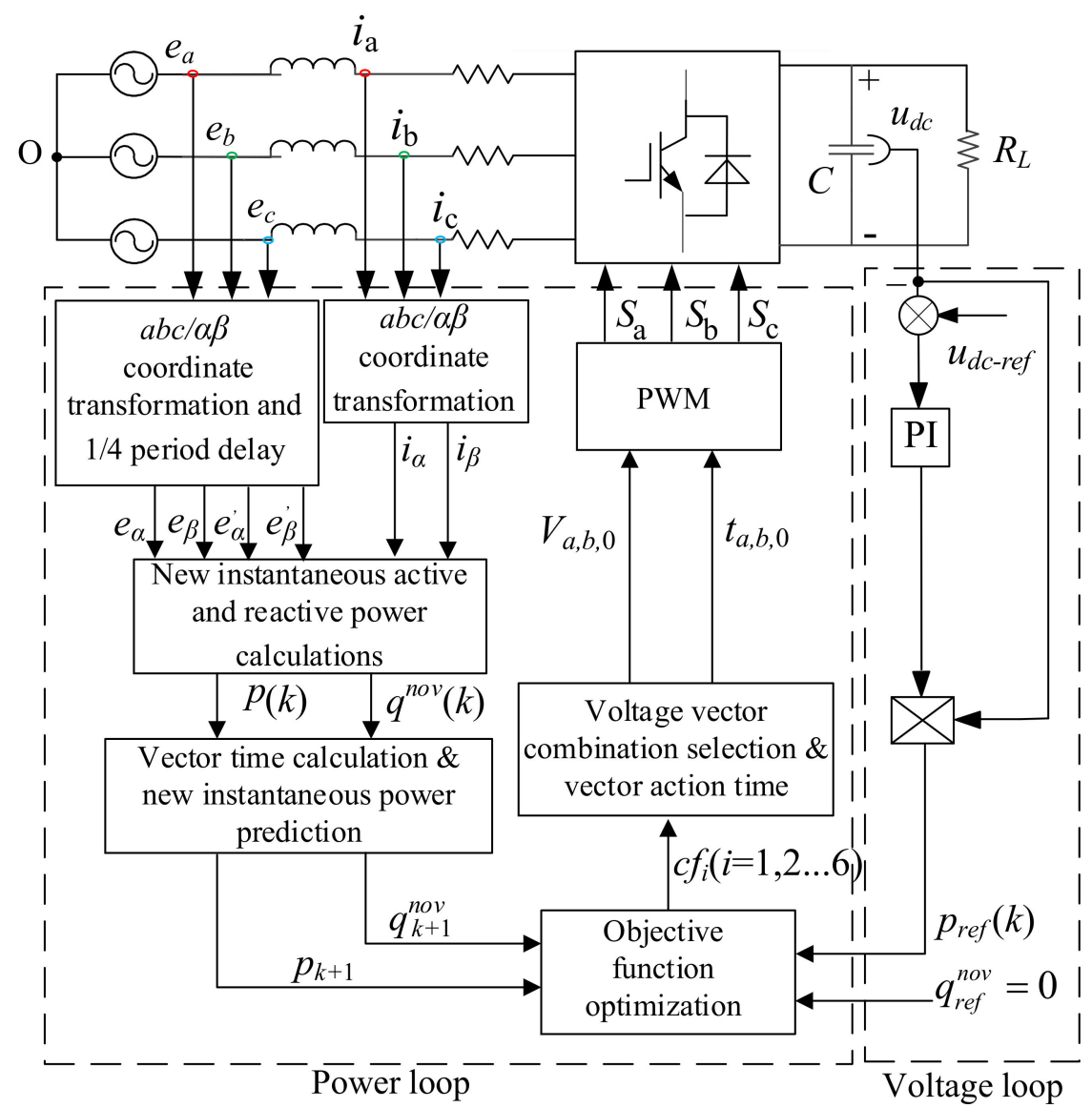

Figure 3. Control diagram of novel FCS-MPDPC.

\section{Simulation and Experimental}

To verify the effectiveness of the new FCS-MPDPC, and an experimental platform is built. In addition, this paper also compares and analyzes the three-vector FCS-MPDPC in the reference [19]. The sampling frequency of the two methods is $10 \mathrm{kHz}$. Table 1 indicates the parameters of the control system. In order to create the unbalanced situation of three-phase power grid, $3 \Omega$ unbalanced resistors are connected in series in the A-phase loop of PWM rectifier.

Table 1. The parameters of control system.

\begin{tabular}{cc}
\hline Parameter & Value \\
\hline DC bus voltage $u_{d c} / V$ & 60 \\
Phase voltage of three-phase network $E_{r m s} / V$ & 20 \\
Grid rated frequency $f / H z$ & 50 \\
Grid side filter inductor $L / m H$ & 7 \\
DC side capacitance $C / \mu F$ & 600 \\
DC side load resistance $R / \Omega$ & 36.5 \\
Sampling frequency $f / H z$ & 10,000 \\
\hline
\end{tabular}

\subsection{The Simulation}

In the Matlab 2021a of MathWorks, the traditional and new FCS-MPDPC simulation models are built, and the simulation results are analyzed.

Under unbalanced power grid conditions, the sinusoidal degree of three-phase current waveforms in the traditional FCS-MPDPC is low, as shown in Figures 4 and 5, especially where the A-phase current waveform is seriously distorted, the three-phase current is 
asymmetric, and the instantaneous power has pulsating components. According to the spectrum analysis of A-phase current, in Figure 6, the THD of A-phase current is 7.13\%, which cannot be obtained to meet the requirements of PWM rectifier grid-connected control; the amplitude of fundamental current is $2.812 \mathrm{~A}$. In addition, there are many low-order harmonics, especially the third and fifth harmonics. Therefore, under unbalanced threephase power grid condition, if the traditional FCS-MPDPC is adopted, the harmonic content of three-phase power grid current is high, which will cause certain "pollution" to the power grid.

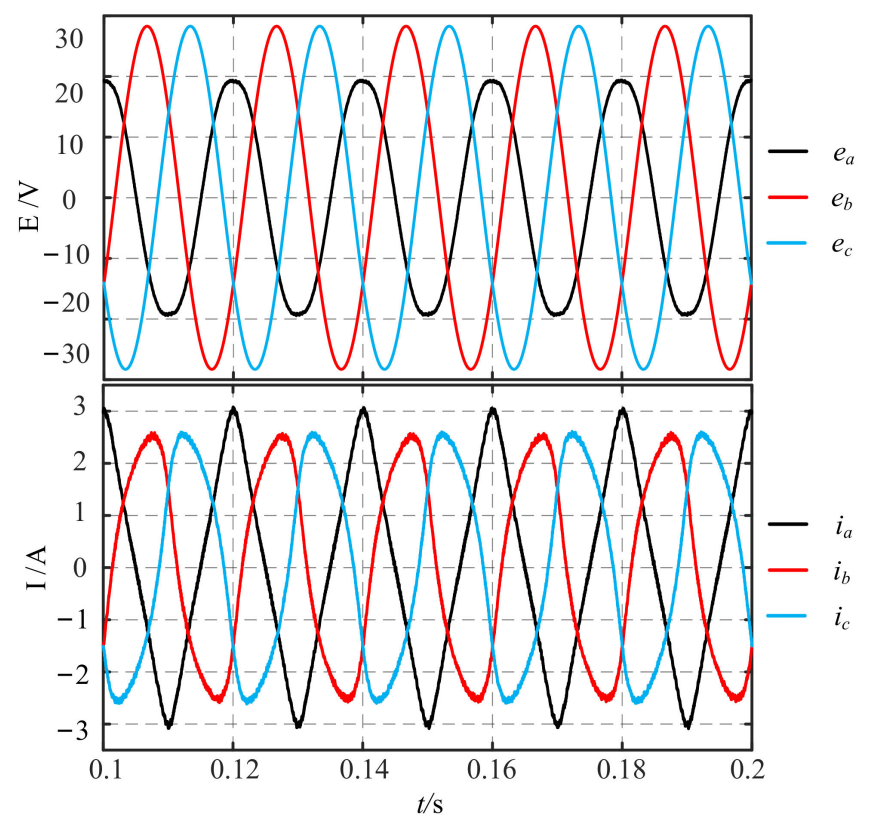

Figure 4. Waveforms of conventional FCS-MPDPC.

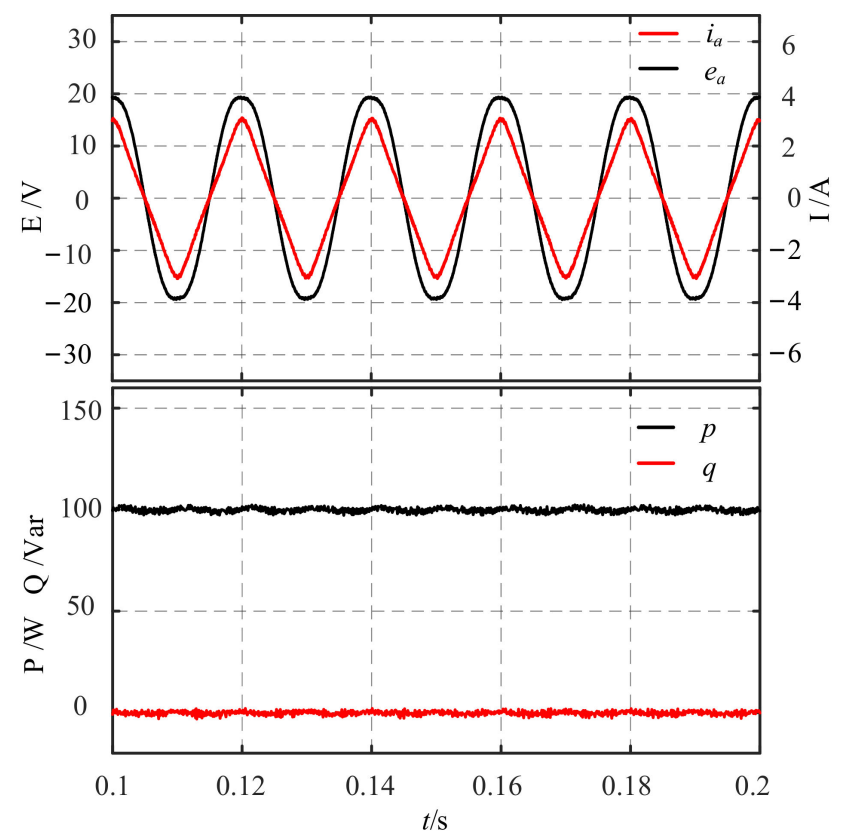

Figure 5. Instantaneous power waveform of conventional FCS-MPDPC. 


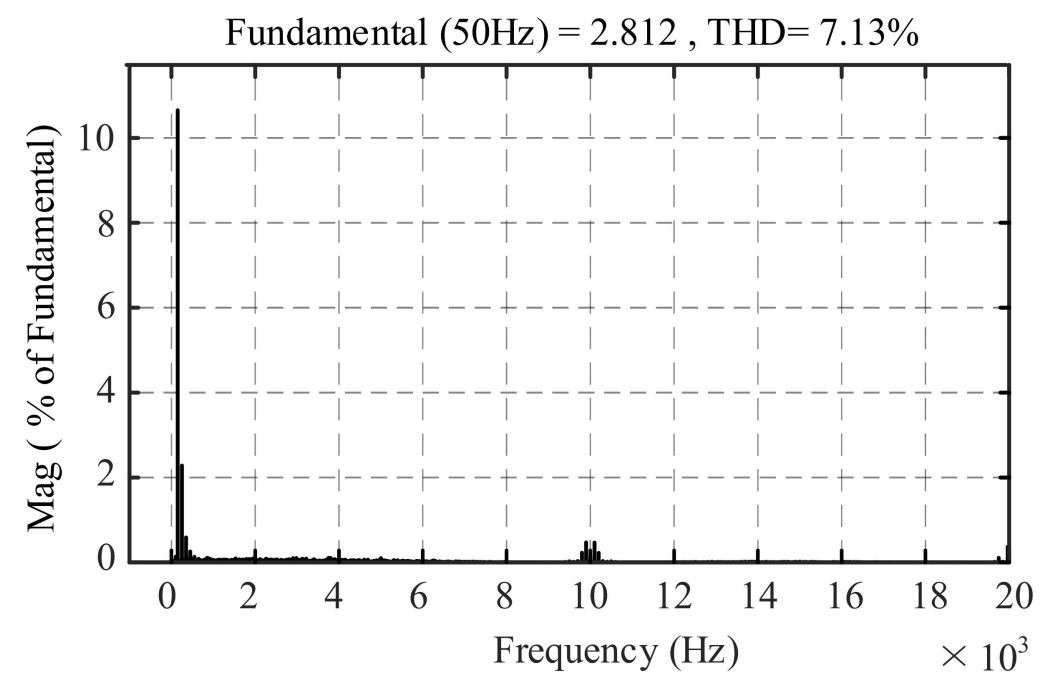

Figure 6. Spectrum analysis of A-phase current of conventional FCS-MPDPC.

It can be seen from Equations (7) and (11), if the second harmonic of DC side voltage is to be suppressed, $p_{c 2}$ and $p_{s 2}$ must be suppressed, but $q_{c 2}$ and $q_{s 2}$ cannot be eliminated, that is, the instantaneous reactive power is not a constant value, but a sinusoidal pulsating component. The unbalanced control method for suppressing the second harmonic component, only the control signal of instantaneous active power can be a fixed value or step command, and the instantaneous reactive power can only be sinusoidal pulsating component.

On the contrary, the new FCS-MPDPC has good steady-state performance. In Figures 7 and 8, the current waveform of three-phase power grid is highly sinusoidal, voltage and current are in the same phase, and the new type of instantaneous power pulsation is small. By analyzing the spectrum of A-phase current, shown in Figure 9, the amplitude of fundamental current is $2.997 \mathrm{~A}$; the THD of current is only $0.97 \%$, which significantly reduces the low-order harmonic component of current, and the high-order harmonic is mainly concentrated in the integral multiple of switching frequency. The filter inductor is simple in design.

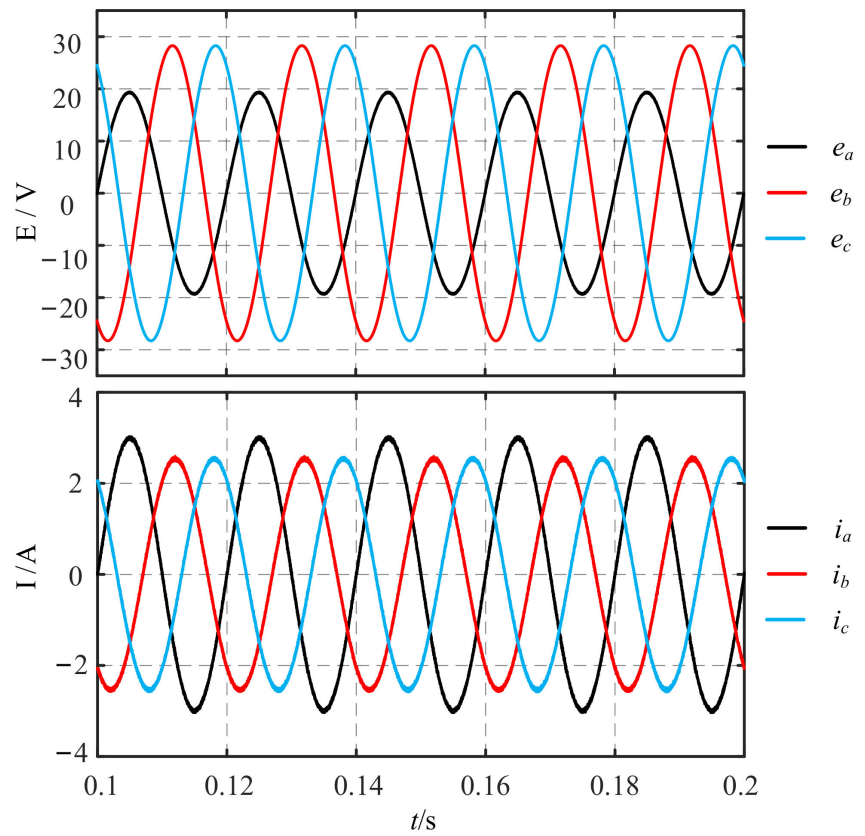

Figure 7. Waveforms of novel FCS-MDPC of novel FCS-MDPC. 


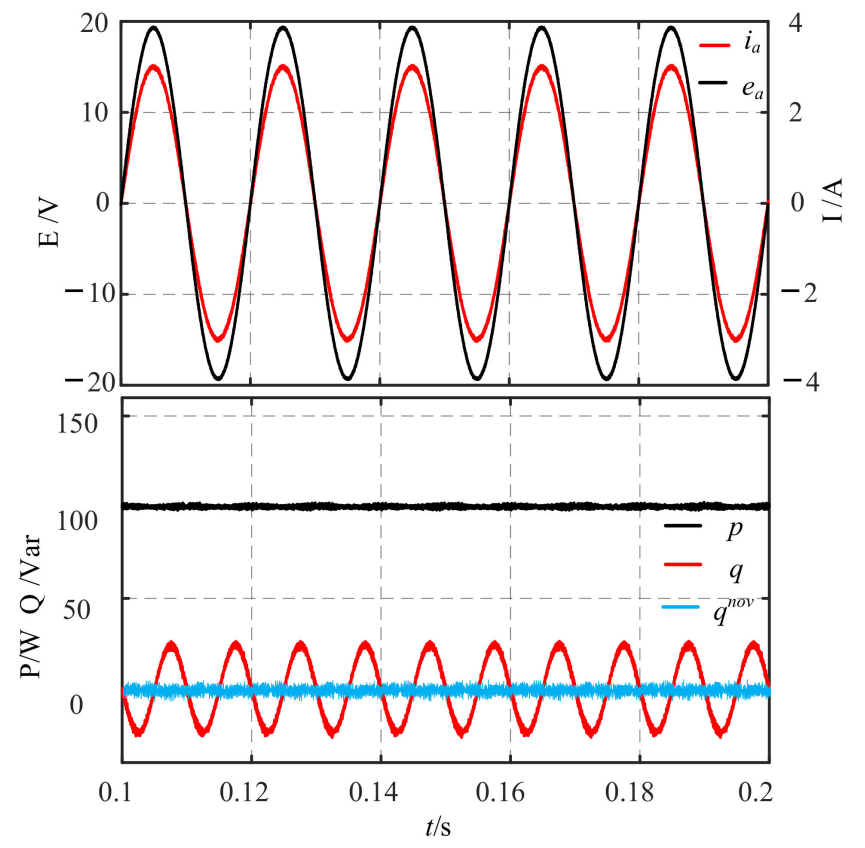

Figure 8. Instantaneous power and new instantaneous power waveform.

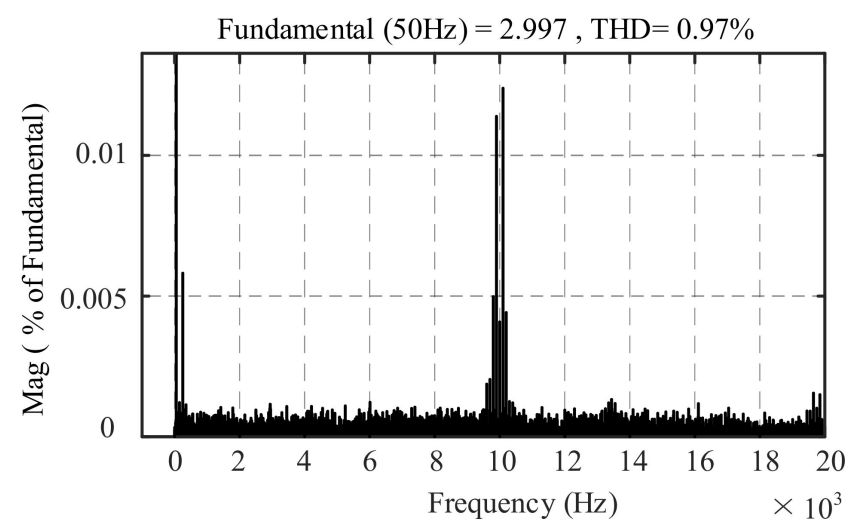

Figure 9. Spectrum analysis of A-phase current of novel FCS-MDPC.

\subsection{The Experiment}

The experiments were carried out on the experimental platform, as shown in Figure 10.

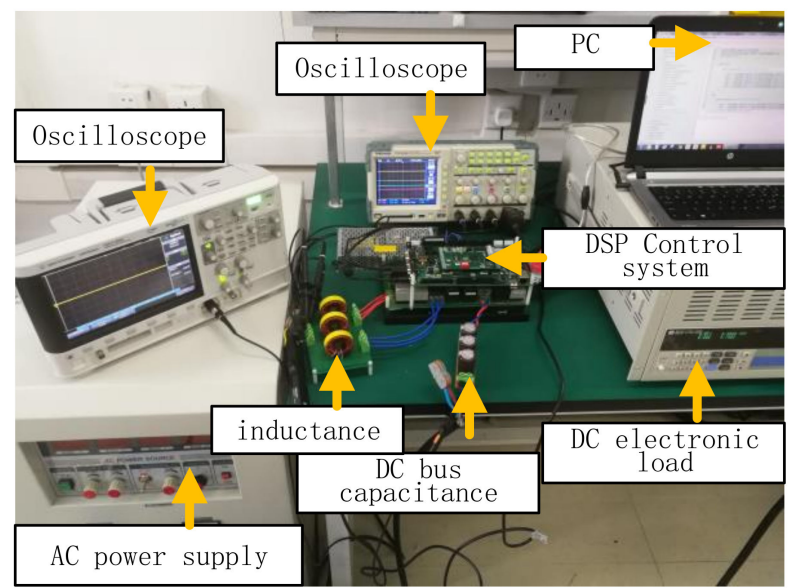

Figure 10. Two-level three-phase PWM rectifier experimental platform. 
Figures 11 and 12, respectively, show the experimental results of traditional and new FCS-MPDPC under power grid unbalance condition. In Figure 11, waveforms of the three-phase current in the traditional FCS-MPDPC is seriously distorted; especially the A-phase current waveform is approximately triangular. Further spectrum analysis of the three-phase current shows that THD of the three-phase current is $6.374 \%, 5.865 \%$ and $5.835 \%$, respectively, which cannot meet the requirements of current THD of PWM rectifier grid-connected control [23].

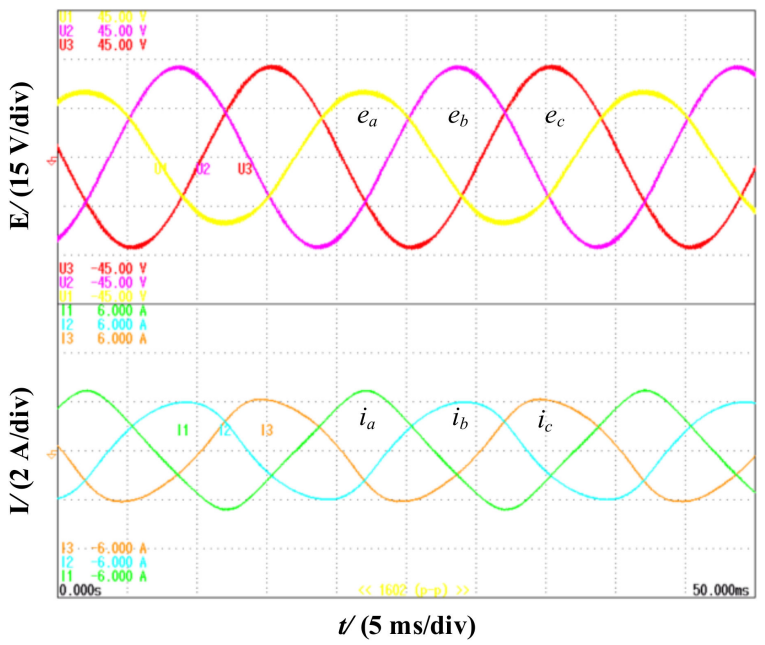

(a)
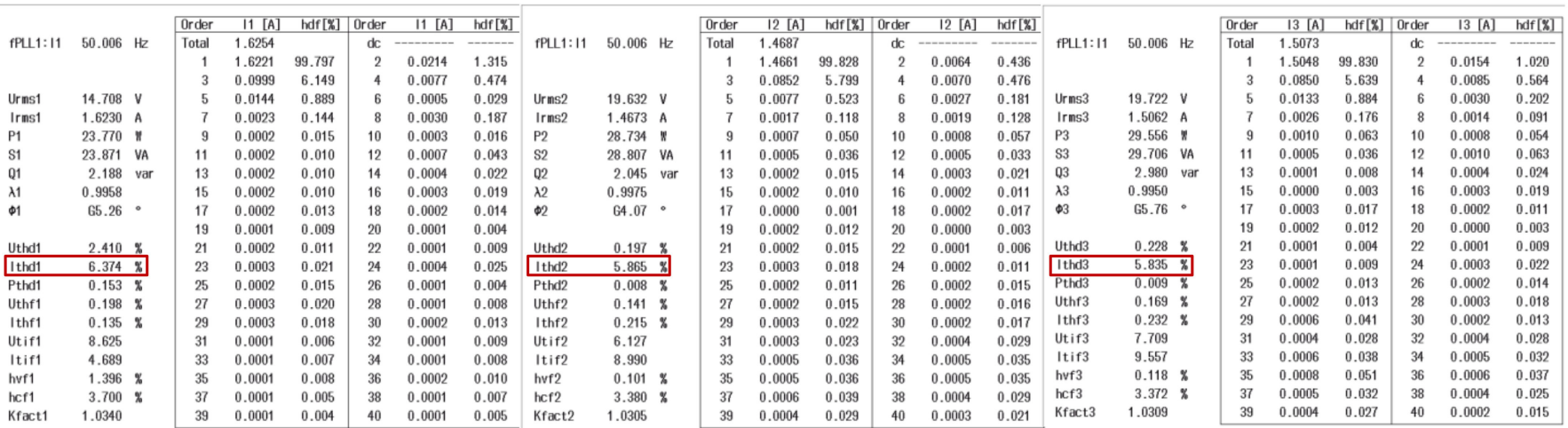

(b)

Figure 11. Experimental results of conventional FCS-MPDPC under unbalanced grid voltages; (a) voltage and current waveforms; (b) spectrum analysis of current.

Under the unbalanced three-phase power grid condition, if the traditional FCSMPDPC is adopted, the harmonic content of three-phase current will be too much, especially the third and fifth harmonics, which will cause certain interference to the power grid.

On the contrary, the new FCS-MPDPC has good steady-state performance. In Figure 12, current waveforms of the three-phase grid has high sinusoidal degree and fewer burrs. Voltage and current are in the same phase. From spectrum analysis of three-phase current, the THD of three-phase current is $0.902 \%, 0.812 \%$ and $0.843 \%$, respectively, which is about $1 / 7$ of the three-phase current THD in traditional FCS-MPDPC. Therefore, compared with the traditional FCS-MPDPC, under grid unbalance conditions, the new FCS-MPDPC can suppress the harmonic component of the current on the grid side and improve the performance of the control system.

In addition, this paper also verifies the effectiveness of the new FCS-MPDPC under three-phase power grid balance. Figure 13 shows the experimental results. Figure 13a shows that the new FCS-MPDPC can suppress the harmonic component of the current and 
reduce the instantaneous active and reactive power pulsation. In Figure 13b, when the new instantaneous active power changes from $70 \mathrm{~W}$ to $140 \mathrm{~W}$, FCS-MPDPC can quickly track the change of the given value while keeping the new instantaneous reactive power. The harmonic analysis of current shows that the THD is small. The low order harmonic content is less, and the high order harmonic is mainly concentrated on the integral multiple of the switching frequency, which is conducive to the filtering of high order harmonic components. It has good dynamic response performance.

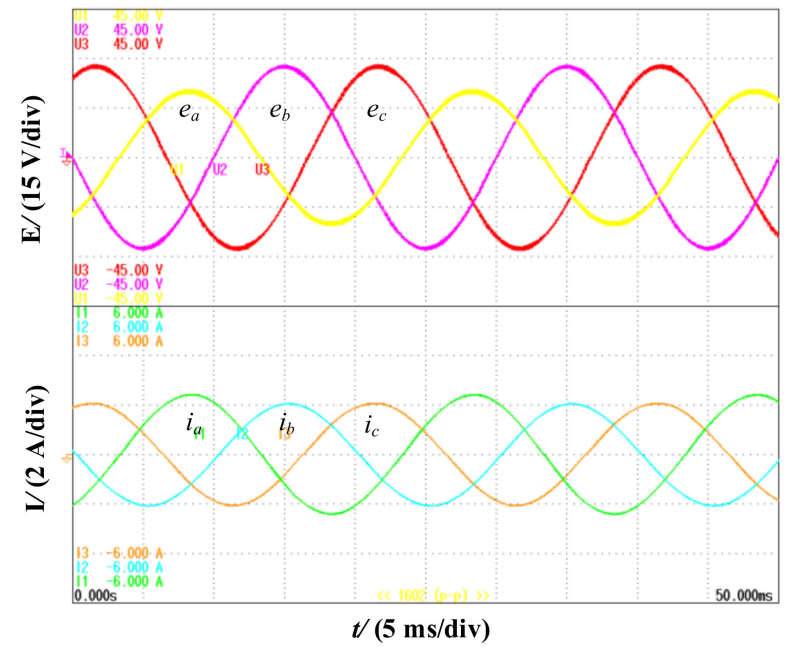

(a)

\begin{tabular}{|c|c|c|c|c|c|c|c|c|c|c|}
\hline \multirow{3}{*}{ fPL1:I1 } & \multirow{2}{*}{\multicolumn{2}{|c|}{$50.011 \mathrm{~Hz}$}} & Order & $11[\mathrm{~A}]$ & $\operatorname{hdf}[\mathrm{x}]$ & Order & $11[\mathrm{~A}]$ & $\operatorname{hdf}[\boldsymbol{x}]$ & \multirow{3}{*}{ fPL1:11 } & \multirow{2}{*}{50.011} \\
\hline & & & \begin{tabular}{|l|} 
Total \\
\end{tabular} & 1.7127 & & dc & & & & \\
\hline & & & 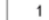 & 1.7126 & 99.996 & 2 & 0.0134 & 0.782 & & \\
\hline & & & 3 & 0.0028 & 0.165 & 4 & 0.0019 & 0.109 & & \\
\hline Urns1 & 14.374 & v & 5 & 0.0051 & 0.297 & 6 & 0.0030 & 0.177 & Urms2 & $19.616 \vee$ \\
\hline Irms1 & 1.7129 & A & 7 & 0.0008 & 0.048 & 8 & 0.0027 & 0.157 & Irns2 & $1.4683 \mathrm{~A}$ \\
\hline P1 & 24.610 & " & 9 & 0.0004 & 0.023 & 10 & 0.0010 & 0.056 & P2 & $28.645 \mathrm{n}$ \\
\hline s1 & 24.622 & VA & 11 & 0.0005 & 0.029 & 12 & 0.0004 & 0.022 & s2 & 28.802 \\
\hline Q1 & 0.789 & var & 13 & 0.0004 & 0.025 & 14 & 0.0003 & 0.019 & Q2 & $3.007 \mathrm{v}$ \\
\hline$\lambda 1$ & 0.9995 & & 15 & 0.0001 & 0.005 & 16 & 0.0006 & 0.037 & $\lambda 2$ & 0.9945 \\
\hline \multirow[t]{2}{*}{ 11 } & 61.84 & • & 17 & 0.0001 & 0.008 & 18 & 0.0004 & 0.023 & $\$ 2$ & 65.99 \\
\hline & & & 19 & 0.0002 & 0.011 & 20 & 0.0002 & 0.014 & & \\
\hline Uthd1 & 0.902 & & 21 & 0.0001 & 0.007 & 22 & 0.0006 & 0.033 & Uthd2 & 0.5789 \\
\hline Ithd1 & 0.902 & 8 & 23 & 0.0001 & 0.008 & 24 & 0.0001 & 0.007 & $\mid 1$ thd 2 & 0.812 \\
\hline Pthd1 & 0.003 & 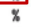 & 25 & 0.0000 & 0.002 & 26 & 0.0003 & 0.015 & Pthd2 & 0.000 \\
\hline Uthf1 & 1.224 & 8 & 27 & 0.0002 & 0.014 & 28 & 0.0002 & 0.009 & Uthf2 & 0.848 \\
\hline Ithf1 & 0.165 & $x$ & 29 & 0.0003 & 0.015 & 30 & 0.0003 & 0.019 & Ithf2 & 0.203 \\
\hline Utif1 & 48.957 & & 31 & 0.0002 & 0.011 & 32 & 0.0004 & 0.026 & Utif2 & 33.789 \\
\hline Itif1 & 6.931 & & 33 & 0.0002 & 0.011 & 34 & 0.0003 & 0.017 & Itif2 & 8.588 \\
\hline hvf1 & 0.288 & $x$ & 35 & 0.0002 & 0.010 & 36 & 0.0001 & 0.007 & hvf2 & $0.121 x$ \\
\hline hcf1 & 0.587 & 8 & 37 & 0.0002 & 0.009 & 38 & 0.0002 & 0.014 & hcf2 & 0.519 \\
\hline Kfact1 & 1.0038 & & 39 & 0.0002 & 0.013 & 40 & 0.0002 & 0.015 & Kfact2 & 1.0056 \\
\hline
\end{tabular}

\begin{tabular}{|c|c|c|c|c|c|c|c|}
\hline rder & $12[\mathrm{~A}]$ & $\operatorname{hdf}[\mathrm{x}]$ & Order & $12[\mathrm{~A}]$ & $\operatorname{hdf}[x]$ & & \\
\hline Total & 1.4683 & & dc & & & FPL1:I1 & $50.011 \mathrm{~Hz}$ \\
\hline & 1.4683 & 99.997 & 2 & 0.0100 & 0.681 & & \\
\hline 3 & 0.0028 & 0.193 & 4 & 0.0007 & 0.051 & & \\
\hline 5 & 0.0041 & 0.282 & & 0.0022 & 0.148 & Urns3 & 19.732 \\
\hline 7 & 0.0009 & 0.059 & 8 & 0.0019 & 0.13 & Irns3 & $1.4724 \mathrm{~A}$ \\
\hline 9 & 0.0004 & 0.028 & 10 & 0.0014 & 0.095 & P3 & 28.903 \\
\hline 11 & 0.0002 & 0.012 & 12 & 0.0009 & 0.064 & S3 & 29.052 \\
\hline 13 & 0.0007 & 0.050 & 14 & 0.0003 & 0.018 & Q3 & 2.947 \\
\hline 15 & 0. & 0.04 & & 0. & 0.0 & $\lambda 3$ & 0.9948 \\
\hline 17 & 0.0001 & 0.007 & 18 & 0.0005 & 0.031 & $\oplus_{3}$ & 65.82 \\
\hline 19 & 0.0003 & 0.021 & 20 & 0.0001 & 0.007 & & \\
\hline 21 & 0.0001 & 0.004 & 22 & 0.0003 & 0.022 & Uthd3 & 0.577 \\
\hline 23 & 0.0001 & 0.008 & & 0.0003 & 0.021 & Ithd3 & 0.843 \\
\hline 25 & 0.000 & 0.014 & & 0.0005 & 0.03 & Pthd3 & 0.000 \\
\hline 27 & 0.0001 & 0.007 & 28 & 0.0000 & 0.003 & Utht & 0.837 \\
\hline 29 & 0.0003 & 0.017 & 30 & 0.0003 & 0.022 & Ithf3 & 0.226 \\
\hline 31 & & 0.009 & 32 & & 0.006 & Utif3 & 33.472 \\
\hline 33 & .0001 & 0.010 & & 003 & 0.020 & Itif3 & 9.154 \\
\hline 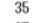 & 0.0002 & 0.012 & & 0.0004 & 0.028 & hvf3 & 0.122 \\
\hline 37 & 0.0001 & 0.005 & 38 & 0.0002 & 0.013 & hcf3 & 0.529 \\
\hline 39 & 0.0001 & 0.005 & 40 & 0.0002 & 0.014 & Kfact3 & 1.0056 \\
\hline
\end{tabular}

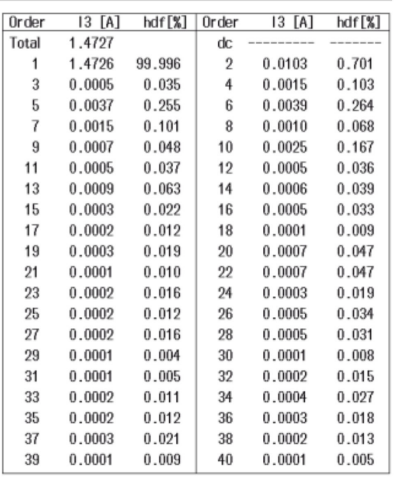

(b)

Figure 12. Experimental results of novel FCS-MPDPC under unbalanced grid voltages; (a) voltage and current waveforms; (b) spectrum analysis of current.

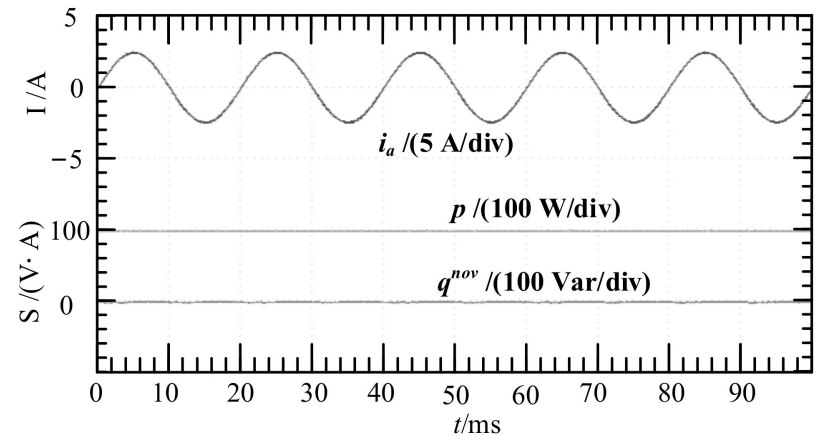

(a)

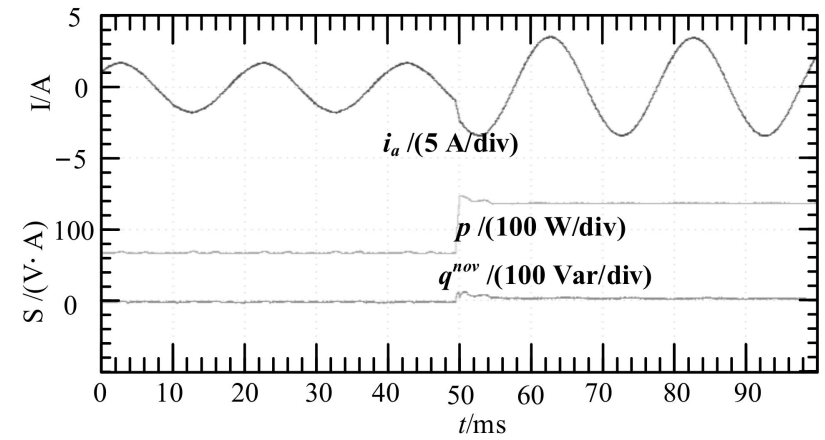

(b)

Figure 13. Experimental results of novel FCS-MPDPC under balanced grid voltages; (a) steady-state waveform; (b) dynamic waveforms. 


\section{Conclusions}

A novel three vector three-phase voltage source PWM rectifier FCS-MPDPC is presented. Under the unbalanced power grid condition, compared with the traditional method, FCS-MPDPC proposed adopts the new instantaneous power theory, redefines the instantaneous reactive power. This method can effectively suppress the harmonic component of current and reduce the instantaneous active power pulsation, which has the advantages of low harmonic content of current on the grid side, fixed switching frequency and small instantaneous power pulsation. Therefore, the new FCS-MPDPC is a control strategy with great practical value.

Author Contributions: Conceptualization, L.T. and M.L.; methodology, L.T. and H.L.; software, L.T.; validation, L.T., H.L. and Y.L.; formal analysis, L.T.; writing —original draft preparation, L.T.; writing - review and editing, M.L.; visualization, H.L. and Y.L. All authors have read and agreed to the published version of the manuscript.

Funding: This research was funded by the Shandong Province Natural Science Foundation, grant number ZR2018BEE032 and a Project of Shandong Province Higher Educational Science and Technology Program, grant number J18KB142.

Conflicts of Interest: The authors declare no conflict of interest.

$\begin{array}{ll}\text { Abbreviations } \\ \text { MPDPC } & \text { Model predictive direct power control } \\ \text { PWM } & \text { Pulse-width modulation } \\ \text { MPC } & \text { Model predictive control } \\ \text { FCS-MPDPC } & \text { Finite control set model predictive direct power control } \\ \text { THD } & \text { Total harmonic distortion }\end{array}$

\section{References}

1. Tarisciotti, L.; Zanchetta, P.; Watson, A.; Clare, J.; Degano, M.; Bifaretti, S. Modulated model predictive control (M2PC) for a 3-phase active front-end. In Proceedings of the 2013 IEEE Energy Conversion Congress and Exposition, Denver, CO, USA, 15-19 September 2013; pp. 1062-1069.

2. Rivera, M. A new predictive control scheme for a VSI with reduced common mode voltage operating at fixed switching frequency. In Proceedings of the 2015 IEEE 5th International Conference on Power Engineering, Energy and Electrical Drives (POWERENG), Riga, Latvia, 11-13 May 2015; pp. 617-622.

3. Riar, B.S.; Scoltock, J.; Madawala, U.K. Model predictive direct slope control for power converters. IEEE Trans. Power Electron. 2017, 32, 2278-2289. [CrossRef]

4. Arif, B.; Tarisciotti, L.; Zanchetta, P. Grid parameter estimation using model predictive direct power control. IEEE Trans. Ind. Appl. 2015, 51, 4614-4622. [CrossRef]

5. Cortés, P.; Rodriguez, J.; Antoniewicz, P.; Kazmierkowski, M. Direct Power Control of an AFE Using Predictive Control. IEEE Trans. Power Electron. 2008, 23, 2516-2523. [CrossRef]

6. Zhang, Y.; Xie, W.; Li, Z.; Zhang, Y. Model Predictive Direct Power Control of a PWM Rectifier with Duty Cycle Optimization. IEEE Trans. Power Electron. 2013, 28, 5343-5351. [CrossRef]

7. Shang, L.; Sun, D. Predictive direct power control of three-Phase grid-connected voltage-sourced inverters. Trans. China Electrotech. Soc. 2011, 26, 216-222.

8. Song, Z.; Chen, W.; Xia, C. Predictive direct power control for three-phase grid-connected converters without sector information and voltage vector selection. IEEE Trans. Power Electron. 2014, 29, 5518-5531. [CrossRef]

9. Bouafia, A.; Gaubert, J.; Krim, F. Predictive direct power control of three-phase PWM rectifier using SVM. IEEE Trans. Power Electron. 2010, 25, 228-236. [CrossRef]

10. Ding, W.; Pan, Z. A new predictive direct power control solution for three-phase grid-connected inverters. Trans. China Electrotech. Soc. 2015, 30, 67-74.

11. Tao, Y.; Wu, Q.; Wang, L.; Tang, W. Voltage sensorless predictive direct power control of three-phase PWM converters. IET Power Electron. 2016, 9, 1009-1018. [CrossRef]

12. Shen, S.; Zhou, Y. UPFC control strategy based on improved predictive direct power control. Guangdong Electr. Power 2018, 31, 93-98.

13. Tang, N.; Xiao, X. Direct power control for sliding mode variable structure of permanent-magnet direct drive wind power generator. Guangdong Electr. Power 2013, 26, 64-69. 
14. Han, Y.; Lin, M.; Hao, L. Triple-state direct power control strategy of three-phase boost type PWM rectifiers. Trans. China Electrotech. Soc. 2013, 28, 208-212.

15. Yao, X.; Wang, X. Research on double switching vector table direct power control of three-phase voltage source PWM rectifier. Electr. Mach. Control. 2015, 19, 71-77.

16. Zhang, Y.; Qu, C.; Li, Z.; Xu, W. Model predictive control and direct power control for PWM rectifiers with active power ripple minimization. IEEE Trans. Ind. Appl. 2016, 52, 4909-4918. [CrossRef]

17. Choi, D.; Lee, K. Dynamic performance improvement of AC/DC converter using model predictive direct power control with finite control set. IEEE Trans. Ind. Electron. 2015, 62, 757-767. [CrossRef]

18. Zhang, Z.; Feng, X.; Fang, H. Ripple-reduced model predictive direct power control for active front-end power converters with extended switching vectors and time-optimized control. IET Power Electron. 2016, 9, 1914-1923.

19. Li, H.; Lin, M.; Ai, J.; Yang, G.; Wang, X.; Le, W. Three-Vector-Based Model Predictive Direct Power Control Strategy for PWM Rectifier. In Proceedings of the 2018 IEEE Energy Conversion Congress and Exposition (ECCE), Portland, OR, USA, 23-27 September 2018; pp. 4039-4045.

20. Vazquez, S.; Marquez, A.; Aguilera, R.P.; Quevedo, D.E.; Leon, J.I.; Franquelo, L.G. Predictive Optimal Switching Sequence Direct Power Control for Grid-Connected Power Converters. IEEE Trans. Ind. Electron. 2015, 62, 757-767. [CrossRef]

21. Akagi, H.; Kanazawa, Y.; Nabae, A. Instantaneous Reactive Power Compensators Comprising Switching Devices without Energy Storage Components. IEEE Trans. Ind. Appl. 1984, IA-20, 625-630. [CrossRef]

22. Suh, Y.; Lipo, T.A. Modeling and analysis of instantaneous active and reactive power for PWM ac/dc converter under generalized unbalanced network. IEEE Trans. Power Deliv. 2006, 21, 1530-1540. [CrossRef]

23. IEEE Recommended Practices and Requirements for Harmonic Control in Electrical Power Systems. IEEE Std 519-1992. 1993; pp. 1-112. Available online: https:/ / ieeexplore.ieee.org/document/210894 (accessed on 18 October 2021). 